\title{
Conserved and plant-unique mechanisms regulating plant post-Golgi traffic
}

\author{
Masaru Fujimoto ${ }^{1}$ and Takashi Ueda ${ }^{1,2 *}$ \\ Department of Biological Sciences, Graduate School of Science, The University of Tokyo, Tokyo, Japan \\ 2 Japan Science and Technology Agency, Precursory Research for Embryonic Science and Technology, Kawaguchi, Japan
}

\section{Edited by:}

Angus S. Murphy, University of

Maryland, USA

Reviewed by:

Stephanie Robert, SLU/Umeå Plant

Science Center, Sweden

Frantisek Baluska, University of Bonn, Germany

*Correspondence:

Takashi Ueda, Department of

Biological Sciences, Graduate School

of Science, The University of Tokyo,

7-3-1 Hongo, Bunkyo-ku, Tokyo

113-0033, Japan

e-mail: tueda@biol.s.u-tokyo.ac.jp
Membrane traffic plays crucial roles in diverse aspects of cellular and organelle functions in eukaryotic cells. Molecular machineries regulating each step of membrane traffic including the formation, tethering, and fusion of membrane carriers are largely conserved among various organisms, which suggests that the framework of membrane traffic is commonly shared among eukaryotic lineages. However, in addition to the common components, each organism has also acquired lineage-specific regulatory molecules that may be associated with the lineage-specific diversification of membrane trafficking events. In plants, comparative genomic analyses also indicate that some key machineries of membrane traffic are significantly and specifically diversified. In this review, we summarize recent progress regarding plant-unique regulatory mechanisms for membrane traffic, with a special focus on vesicle formation and fusion components in the post-Golgi trafficking pathway.

Keywords: coat protein complex, dynamin-related protein, membrane trafficking, Rab GTPase, tether, SNARE

\section{INTRODUCTION}

Eukaryotic cells are distinguished by the presence of internal membrane-bound organelles, including mitochondria, plastids, peroxisomes, and other single membrane-bound organelles. Two different underlying mechanisms have been proposed for the emergence of these organelles. Mitochondria and plastids, which have a double-membrane envelope in principle, arose respectively through the symbiotic incorporation of $\alpha$-proteobacteria and cyanobacteria by the ancestral eukaryotic cell (Barbrook et al., 2006; Embley and Martin, 2006). In contrast, organelles bound by a single membrane layer [e.g., the endoplasmic reticulum (ER), Golgi apparatus, trans-Golgi network (TGN), plasma membrane (PM), and a series of endosomal compartments], are thought to have evolved autogenously from preexisting single membrane components in ancient proto-eukaryotic cells (Cavalier-Smith, 1987, 2002). These single membrane-bound organelles are connected with each other through a trafficking system mediated by vesicular and/or tubular membranous transport carriers, known as membrane trafficking. Membrane trafficking consists of several sequential processes: the formation of cargo-bearing vesicles or tubules from donor membranes, targeted delivery of transport carriers, and tethering of carriers to target membranes, followed by membrane fusion (Figure 1). These processes involve specific sets of regulatory machinery. For example, coat protein complexes (CPCs) and dynamin-related GTPases (DRPs) participate in the formation of vesicular or tubular carriers; CPCs facilitate cargo selection and membrane deformation, and DRPs take part in the tubulation and/or scission of donor membranes (Figure 1; Bonifacino and Glick, 2004; Praefcke and McMahon, 2004). Rab GTPase, a member of the Ras superfamily, tethers, and soluble $\mathrm{N}$-ethylmaleimide-sensitive factor attachment protein receptors (SNAREs) are responsible for the targeting and subsequent tethering and fusion of carriers to target membranes (Figure 1; Chen and Scheller, 2001; Seabra and Wasmeier, 2004; Yu and Hughson, 2010). Each subfamily of these machinery components performs a function similar to that of other paralogs, but at a specific subcellular location or as part of a distinct transport pathway (Bonifacino and Glick, 2004).

Modern phylogenetic studies suggest that eukaryotes are comprised of five major supergroups: Amoebozoa; Opisthokonta; Archaeplastida; Excavata; and Stramenopiles, Alveolates and Rhizaria together with Cryptophyte, Centrohelid, Telonemid, and Haptophyte (SAR + CCTH; Burki et al., 2009). Owing to the recent accumulation of genomic resources among these five supergroups, molecular evolutionary analyses have been yielding information about the emergence and establishment of membrane trafficking components. Comparative genomic and phylogenetic analyses of CPCs (Schledzewski et al., 1999), DRPs (Elde et al., 2005; Miyagishima et al., 2008), Rab GTPases (Brighouse et al., 2010; Elias et al., 2012), tethers (Koumandou et al., 2007), and SNAREs (Dacks and Doolittle, 2002; Yoshizawa et al., 2006) sampled from a broad range of eukaryotic lineages have revealed that similar sets of paralogous subgroups of these machinery components are often shared among these supergroups. This conservation suggests that the basic framework of membrane traffic was already established before the last common eukaryotic ancestor, which is commonly shared among extant descendant eukaryotic lineages (Dacks et al., 2009). However, these analyses also demonstrated that each eukaryotic lineage occasionally acquired lineage-specific new subgroups and/or expanded specific subfamilies, probably by lineage-specific gene multiplication and the accumulation of mutations. Such genes are predicted to be associated with the lineage-specific differentiation of organelle functions and membrane trafficking pathways.

The lineage-specific expansion and diversification of machinery components for membrane trafficking are also evident in plant 


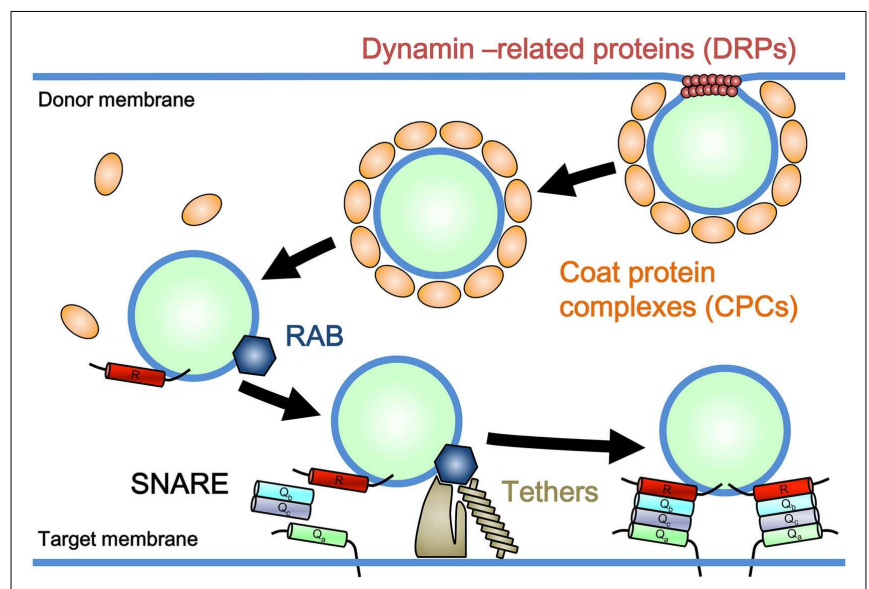

FIGURE 1 | Model for a general mechanism of membrane trafficking. Coat protein complexes (CPCs) and dynamin-related GTPases (DRPs) participate in the formation of vesicular or tubular carriers. CPCs facilitate cargo selection and membrane deformation, and DRPs take part in the tubulation and/or scission of donor membranes. Rab GTPase promotes the tethering of membrane carriers to the target membrane through effector molecules (Tethers), which is followed by SNARE-mediated membrane fusion.

lineages, especially in land plants (Embryophytes). For example, some specific Rab GTPase, component of tethering factors, and SNARE subfamilies are remarkably expanded and functionally diversified (Vernoud et al., 2003; Sanderfoot, 2007; Woollard and Moore, 2008; Saito and Ueda, 2009; Chong et al., 2010). Moreover, plant-unique molecular machineries, which are structurally distinct from closely related homologs conserved in a wide range of eukaryotic organisms, take part in fundamental membrane trafficking processes in plant cells (Ebine et al., 2008, 2011; Fujimoto et al., 2010; Van Damme et al., 2011). This review summarizes recent advances in the study of plant post-Golgi trafficking pathways, focusing on unique aspects of the plant system.

\section{COAT PROTEIN COMPLEXES}

A single round of trafficking between two organelles begin with the formation of transport vesicles from the donor organelle (Figure 1). In this process, cytosolic CPCs perform pivotal roles in membrane deformation and cargo recruitment. Three classes of CPCs are widely utilized in a range of eukaryotic organisms (Schledzewski et al., 1999; Singh and Gupta, 2004; Elde et al., 2005; Dacks and Field, 2007): coat protein complex II (COPII) mediates ER-to-Golgi trafficking, coat protein complex I (COPI) mediates intra-Golgi and Golgi-to-ER trafficking (Lee et al., 2004), and clathrin-based complexes are involved in multiple steps in post-Golgi trafficking (McMahon and Mills, 2004). These three CPCs are likely to have a common ancestral origin, which may be also the origin of the nuclear pore complex (Devos et al., 2004).

Clathrin-based complexes mainly comprise clathrin coats and adaptor molecules such as cargo- or lipid-binding proteins. The clathrin coat is made up of a three-legged structure called the triskelion, each leg of which consists of a heavy chain (CHC) and a light chain (CLC) (Brodsky et al., 2001). Triskelia assemble into a lattice surrounding the membrane bud on the TGN, PM, endosomes, and lysosomes/vacuoles, and concentrate adaptors bound with cargo, leading to the loading of proteins and lipids into forming vesicles (Crowther and Pearse, 1981; Hanover et al., 1984). Although the overall architecture is well conserved among clathrin coats in eukaryotic lineages, including plants (Coleman et al., 1987), the triskelion structure of the plant clathrin coat exhibits several distinct characteristics. The plant triskelion has a higher molecular mass and longer arms than the mammalian triskelion (Mersey et al., 1985; Depta and Robinson, 1986; Coleman et al., 1987; Depta et al., 1987), suggesting that unique properties were added to plant clathrin coats during evolution.

Adaptor protein (AP) complexes AP-1 through AP-5 are central organizers that mediate cargo recognition at forming vesicles in post-Golgi trafficking pathways (Pearse and Robinson, 1984; Dell'Angelica et al., 1997, 1999; Hirst et al., 1999, 2011; Robinson and Bonifacino, 2001). Each AP complex consists of four subunits called adaptins, which are large $\alpha / \gamma / \delta / \varepsilon / \zeta$ and $\beta$ subunits, a medium $\mu$ subunit, and a small $\sigma$ subunit (Boehm and Bonifacino, 2002; Hirst et al., 2011). During vesicle formation, AP complexes link the clathrin lattice and select membrane cargos and lipids. AP complexes also bind other accessory proteins, which in turn regulate the assembly and disassembly of the coat (Bonifacino and Traub, 2003). All of these AP complexes are observed among all eukaryotic lineages with sporadic secondary loss in some clades, indicating an ancient origin for all five complexes (Hirst et al., 2011). Currently, each AP complex is assigned to a distinctive location and function: bi-directional trafficking between endosomes and the TGN for AP-1 (Boehm and Bonifacino, 2002; Robinson et al., 2010), endocytosis from the PM for AP-2 (Bar et al., 2009; Jackson et al., 2010), traffic from early endosomes/TGN to late endosomes and lysosomes/vacuoles for AP-3 (Dell'Angelica, 2009; Niihama et al., 2009; Feraru et al., 2010), TGN-to-endosome trafficking for AP-4 (Burgos et al., 2010), and trafficking around the late endosomes for AP-5 (Hirst et al., 2011). Among these AP complexes, AP-1 and AP-2 have been demonstrated to interact with clathrin, while other complexes are thought to be able to act without associating with clathrin. The ancient origin of the AP complexes suggests that their functions are also conserved in plants, which should be verified in future studies.

In addition to the conserved AP complexes, land plants have a unique adaptor-like protein, TPLATE, which contains a domain similar to $\beta$-adaptin and interacts with clathrin (Van Damme et al., 2006, 2011). TPLATE is specifically targeted to the expanding cell plate and the particular region of the PM around the site of fusion between the expanding cell plate and the mother cell, to which clathrin is also localized (Van Damme et al., 2011). Thus, TPLATE is expected to act in clathrin-mediated endocytosis during cell plate formation. Restriction of the lateral diffusion of KNOLLE, a SNARE protein, at the PM of mother cells during cytokinesis and its removal from the PM are accomplished by clathrin-mediated endocytosis (Segui-Simarro et al., 2004; Boutte et al., 2010). KNOLLE is a possible cargo of TPLATE-mediated endocytosis.

\section{DYNAMIN-RELATED PROTEINS}

Dynamin-related proteins (DRPs) are large GTPases that regulate membrane fission, fusion, and tubulation during diverse cellular 
activities such as endocytosis, cytokinesis, vacuolar sorting, fission and fusion of mitochondria, biogenesis of peroxisomes, and the maintenance of ER morphology (Praefcke and McMahon, 2004; Hu et al., 2009). In many cases, distinct DRP proteins are assigned to fulfill different cellular functions. However, in Trypanosoma bru$c e i$, a protist belonging to the Excavata supergroup, a single DRP mediates both mitochondrial division and post-Golgi trafficking, including endocytosis (Chanez et al., 2006). By contrast, in the SAR + CCTH supergroup, the DRP protein that acts in endomembrane trafficking has not been found thus far, while DRPs acting in mitochondrial and/or plastid divisions have been identified in this supergroup (Miyagishima et al., 2008; van Dooren et al., 2009). These lines of evidence might suggest that an ancient function of DRPs was the regulation of membrane remodeling associated with mitochondrial endosymbiosis, although it is also plausible that DRPs for membrane trafficking were secondarily lost during evolution of the SAR + CCTH lineage. It has also been reported that some bacterial species possess DRP-like proteins that are able to deform lipid bilayers, implying a possible prokaryotic origin of this protein family (Low and Lowe, 2006; Burmann et al., 2011).

Among DRP family members, dynamin is the bestcharacterized member that acts in clathrin-mediated trafficking in animal cells (Sever, 2002). During clathrin-coated vesicle (CCV) formation, dynamin assembles into helical or ring-shaped structures at the neck of clathrin-coated buds (Takei et al., 1995), and constricts, severing the bud neck membrane in a GTP hydrolysisdependent manner (Sweitzer and Hinshaw, 1998; Macia et al., 2006). Animal dynamin contains five distinct domains: the $N$ terminal GTPase domain; a middle domain that mediates intermolecular interaction during self-assembly; a GTPase-effector domain (GED), which stimulates the GTPase activity required to enact structural change in a dynamin polymer; a pleckstrin homology $(\mathrm{PH})$ domain, which mediates binding to the membrane phosphoinositide; and a proline-rich domain (PRD), which is required for the recruitment of dynamin to clathrin-coated pits (Heymann and Hinshaw, 2009). The former three domains are conserved among almost all DRP proteins. DRPs with a domain configuration similar to that of dynamin, which also harbor the two additional domains, have been observed only in metazoa and land plants (Chanez et al., 2006; Miyagishima et al., 2008; Heymann and Hinshaw, 2009).

Most land plants' genomes contain six types of DRPs: DRP1DRP4, DRP5A, and DRP5B (Hong et al., 2003; Miyagishima et al., 2008). Of these subfamilies, two structurally different DRPs, DRP1, and DRP2, are involved in clathrin-dependent trafficking events including endocytosis and cell plate formation (Figure 2; Hong et al., 2003; Kang et al., 2003; Collings et al., 2008; Fujimoto et al., 2008, 2010; Konopka et al., 2008; Taylor, 2011). DRP2 shares overall domain organization with animal dynamin, while DRP1 lacks the PH domain and PRD; a DRP with a similar structure is only found in green plants (Hong et al., 2003). In spite of the similarity in the overall domain structure between plant DRP2 and animal dynamin, the GTPase domain of animal dynamin exhibits greater similarity to the GTPase domains of DRP1 members than to that of DRP2 (e.g., $66 \%$ identity to A. thaliana DRP1A, and $27 \%$ identity to $A$. thaliana DRP2B). These lines of evidence raise the possibility that complementary functions of plant DRP2 and
DRP1 are required to fulfill the function in clathrin-mediated trafficking events, which animal dynamin executes by itself. In a consistent manner, these two subfamilies of DRPs interact with each other and assemble together with clathrin at discrete foci at the PM (Fujimoto et al., 2010). Cooperative action of two structurally distinct DRPs in the same membrane scission event has not been reported in other organisms; thus, plants appear to have developed a unique mechanism for endocytic vesicle formation.

\section{Rab GTPases}

Rab GTPases, which comprise the largest family in the Ras superfamily, act as molecular switches to regulate the targeting and tethering of transport carriers to target membranes by cycling between GTP-bound active and GDP-bound inactive states (Figure 1; Saito and Ueda, 2009). The activation of Rab GTPases occurs with the exchange of bound GDP for GTP, which is catalyzed by guanine nucleotide exchange factor (GEF). GTP-bound Rab GTPases interact with specific effector molecules that evoke downstream reactions including the tethering of transport carriers to target membranes by tethers (Grosshans et al., 2006). Tethering between two membranes is mediated by a group of multi-subunit complexes (e.g., HOPS, TRAPP, and Exocyst) and/or long fibrous proteins (e.g., EEA1 and p115/Uso1p), most of which act as effectors of Rab GTPases (Cai et al., 2007; Markgraf et al., 2007). Because Rab GTPases exhibit a much greater degree of phylogenetic diversification than other tethering components, they are thought to be vital players in the diversification of the endomembrane system (Dacks and Field, 2007; Gurkan et al., 2007; Elias, 2010). Recent comprehensive genomic analysis has suggested that the last common eukaryotic ancestor harbored at least 23 groups of Rab GTPases (Elias et al., 2012) - substantially more than have been found in many extant eukaryotic organisms, including plants. Thus, the secondary loss of Rab GTPases (and the acquisition of new ones) occurred in a wide range of eukaryotes during evolution.

Plant Rab GTPases also appear to have followed a unique path of diversification and evolution. The genome of A. thaliana contains 57 Rab GTPases that are classified into eight groups (RABA-RABH). Each group exhibits a high degree of similarity to animal RAB1, RAB2, RAB5, RAB6, RAB7, RAB8, RAB11, or RAB18 (Rutherford and Moore, 2002; Vernoud et al., 2003). Most land plants possess these eight groups in theory, with a few additional members of unknown function in basal land plants (Rensing et al., 2008; Banks et al., 2011). Compared with other eukaryotic lineages, one distinct feature of the land plant Rab GTPase is extreme expansion of the RABA/RAB11 group (Rutherford and Moore, 2002). In A. thaliana, 26 of 57 Rab GTPases belong to this group, which are further divided into six subgroups, RABA1 through RABA6 (Rutherford and Moore, 2002). In contrast, three of 66 and two of 11 RAB GTPases in Homo sapiens and Saccharomyces cerevisiae, respectively, are members of the RAB11 group (Pereira-Leal and Seabra, 2001; Stenmark and Olkkonen, 2001).

Yeast and animal RAB11 members function at multiple steps of post-Golgi trafficking pathways (Benli et al., 1996; Ullrich et al., 1996; Jedd et al., 1997; Chen et al., 1998; Strickland and Burgess, 2004). In addition, in land plants, RABA members have been shown to localize around the TGN (Ueda et al., 1996; de Graaf et al., 2005; Chow et al., 2008; Szumlanski and Nielsen, 2009), 


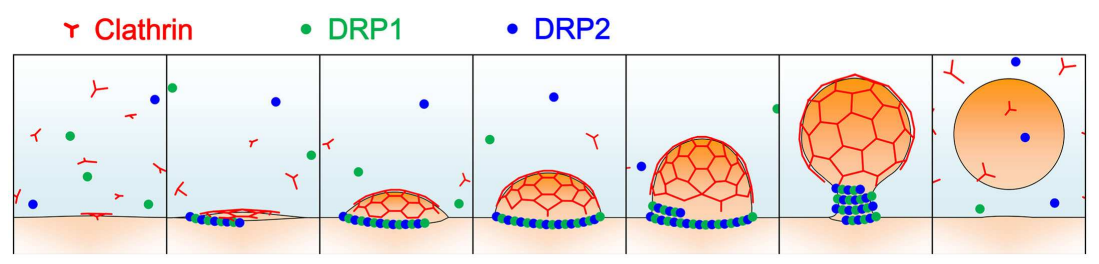

FIGURE 2 | A schematic illustration of clathrin-coated vesicle formation in land plants. Light blue represents the cytosol; orange, and red lines represent the donor membrane and the clathrin coat, respectively; and green and blue dots represent DRP1 and DRP2 proteins, respectively. which also acts as the early endosome in plant cells (Dettmer et al., 2006; Viotti et al., 2010). The diversity of RABA/RAB11 members in land plants suggests that plant-unique functions are assigned to members of this group, some of which are demonstrated by recent studies. For example, RABA2 and A3 are involved in cell plate formation (Chow et al., 2008), and RABA1 and RABA4 are required for normal tip growth of pollen tubes and root hairs (Preuss et al., 2004; de Graaf et al., 2005; Szumlanski and Nielsen, 2009). It has also been proposed that the function of RABA is associated with the biogenesis and degradation of the cell wall during fruit development (Zainal et al., 1996; Lu et al., 2001; Abbal et al., 2008; Lycett, 2008).

The diversification of the RAB5 group is another distinctive feature of the plant Rab GTPase. RAB5 is a broadly conserved Rab GTPase, and regulates a wide range of early endocytic trafficking in animal cells (Somsel Rodman and Wandinger-Ness, 2000; Benmerah, 2004). Orthologs of animal RAB5 are also conserved in all plant species whose genomes have been sequenced thus far, with the exception of a unicellular rhodophyte, Cyanidioschyzon merolae (Matsuzaki et al., 2004). Land plants also harbor another plantunique type of RAB5 molecule, the ARA6/RABF1 group, which is structurally distinct from conventional RAB5 (Ebine and Ueda, 2009). The $A$. thaliana genome has three RAB5-related genes: two conventional type RAB5, RHA1/RABF2a, and $A R A 7 / R A B F 2 b$; and one plant-unique $R A B 5, A R A 6 / R A B F 1$ (Ueda et al., 2001). All of the three RAB5s in A. thaliana have been detected on multivesicular endosomes (MVEs) using electron microscopy (Haas et al., 2007), and are activated by the same GEF, VPS9a (Goh et al., 2007). However, the subcellular localizations of two types of RAB5 did not overlap completely when their localization was compared in the same cell (Ueda et al., 2004), and the overexpression of constitutively active ARA6 and ARA7 conferred different effects on a partial loss-of-function mutant of VPS9a, vps9a-2 (Goh et al., 2007).

Recently, we have successfully demonstrated the functional diversification between these conventional and plant-unique types of RAB5 in A. thaliana. Genetic, biochemical, and imaging analyses indicated that ARA6 acts in the trafficking pathway from MVEs to the PM, while conventional RAB5 is involved in the trafficking pathway between MVEs and vacuoles (Ebine et al., 2011). The ara6 mutation resulted in hypersensitivity to salinity and osmotic stresses, and overexpression of constitutive active ARA6 conferred salinity stress tolerance to A. thaliana plants (Ebine et al., 2011, 2012). Possible involvement of ARA6 homologs in the stress response has also been reported for other land plant species (Bolte et al., 2000; Zhang et al., 2009). Considering with that ARA6 homologs are well conserved among land plants and rather sporadic in algal lineages, it may be adaptive for land plants to retain the trafficking pathway involving the ARA6-type RAB5 for survival in terrestrial conditions.

Another class of small GTPase, Rho-like GTPases of plants (ROP), has recently been demonstrated to have regulatory roles in plant membrane trafficking, which is required for the auxinmediated establishment of cell polarity (Chen et al., 2012; Lin et al., 2012; Nagawa et al., 2012). Directional transport of auxin depends on a family of auxin efflux carriers known as PIN-FORMED (PIN) proteins, which undergo constitutive endocytic recycling (Dhonukshe et al., 2007, 2008; Kleine-Vehn et al., 2011). In the roots, auxin affects its own transport by inhibiting the clathrinmediated endocytosis of PIN1 and PIN2, which is mediated by Auxin Binding Protein 1 (ABP1; Paciorek et al., 2005; Robert et al., 2010), as well as the downstream signaling molecules ROP6 and ROP-interactive CRIB motif containing protein 1 (RIC1; Chen et al., 2012; Lin et al., 2012). In addition, ROP and RIC have been shown to act in the morphogenesis of leaf epidermal cells. Auxin and ABP1 promote interdigitation of epidermal pavement cells by activating a signaling pathway involving ROP2 and RIC4 (Fu et al., 2005; Xu et al., 2010), which causes the accumulation of cortical actin microfilaments, thereby resulting in the local inhibition of clathrin-dependent endocytosis and asymmetric distribution of PIN1 (Nagawa et al., 2012). Rho GTPase-mediated inhibition of endocytosis is also centrally involved in the establishment of cell polarity in animal systems (Izumi et al., 2004; Harris and Tepass, 2008). Thus, the plant appears to have developed its multicellular body plan by recruiting the common mechanism of polarity regulation, as well as by adding plant-specific innovations such as ABP1 and RICs (Napier et al., 2002; Nagawa et al., 2010).

\section{TETHERS}

Some of proteins that mediate the tethering of transport vesicles to target membranes also appear to be diversified in a unique way in plants. A comparative genomic analysis suggested that each tethering complex has an ancient and independent origin; a set of non-homologous tethering complexes is conserved across all eukaryotic lineages, with frequent secondary losses (Koumandou et al., 2007). Acquisition of the non-homologous tethering complexes may be the other driving force for the diversification of membrane trafficking pathways, in addition to the paralogous expansion observed in the Rab and SNARE families.

While the obvious orthologs of long fibrous tethers have not been found, the components of tethering complexes are well conserved in plants (Koumandou et al., 2007). In A. thaliana, 
components of the HOPS/CORVET complexes residing on vacuolar membranes and pre-vacuolar compartments are involved in vacuolar biogenesis and transport to vacuoles (Rojo et al., 2001, 2003; Niihama et al., 2009). The TRAPP complex, which is further divided into TRAPPI and TRAPPII, is required for cell plate formation (Thellmann et al., 2010). The importance of the exocyst complex in various secretion-related events, including tip growth of pollen tubes and root hairs, hypocotyl elongation, deposition of seed coat pectin, pollen acceptance at the stigma, and pathogen responses, has also been reported (Cole et al., 2005; Synek et al., 2006; Hala et al., 2008; Chong et al., 2010; Kulich et al., 2010; Pecenkova et al., 2011). The GARP complex is also involved in pollen tube growth (Lobstein et al., 2004; Guermonprez et al., 2008), as well as resistance to heat and osmotic stresses (Lee et al., 2006).

Among the tethering complexes in land plants, the exocyst complex appears to be assigned to uniquely diversified functions in exocytosis-related events. The exocyst consists of eight evolutionarily conserved subunits, SEC3, SEC5, SEC6, SEC8, SEC10, SEC15, EXO70, and EXO84, whose assembly mediates the tethering of secretory vesicles to the target PM during the last step of exocytosis (Munson and Novick, 2006). Among the exocyst subunits, the EXO70 family exhibits remarkable expansion in land plants. In contrast to a single copy of the EXO70 gene in most of opisthokonta genomes, multiple EXO70 genes have been observed in a variety of land plant genomes: 13 in Physcomitrella patens; 23 in A. thaliana and Populus trichocarpa; and 41 in Oryza sativa (Chong et al., 2010), which can be divided into three families comprising nine subfamilies (Elias et al., 2003; Synek et al., 2006; Chong et al., 2010).

Although the functions of the majority of EXO70 family proteins remain unknown, several $A$. thaliana EXO70 members are localized to endosomal compartments including the TGN/early endosome (Chong et al., 2010). Recently, a unique function of an A. thaliana EXO70 family member, Exo70E2, has been reported. EXO70E2 was localized to spherical double-membrane structures resembling autophagosomes and were named exocyst-positive organelles (EXPOs; Wang et al., 2010). Intriguingly, standard markers for conventional organelles (including the Golgi apparatus; TGN and early endosomes; MVE/late endosomes; and autophagosomes) did not occur on EXPOs (Wang et al., 2010), and brefeldin A and wortmannin did not affect EXPO distribution. EXPOs have been suggested to mediate a form of unconventional protein secretion unique to land plants: the transport of cytosolic proteins to the cell exterior (Wang et al., 2010). Additional studies of other EXO70 family members, as well as functional analyses of other exocyst components, would lead to understanding the unique and diverse exocytic mechanisms that plants have acquired during the course of evolution.

\section{SNARE FAMILY PROTEINS}

At the final step of a single round of trafficking, SNARE family proteins, which are evolutionarily conserved integral or peripheral membrane proteins, execute membrane fusion between transport carriers and target membranes (Figure 1; Jahn and Scheller, 2006; Wickner and Schekman, 2008; Saito and Ueda, 2009). The SNARE family consists of four subgroups, Qa-, Qb-, Qc-, and
R-SNAREs, which are classified according to the presence of a conserved glutamine $(\mathrm{Q})$ or arginine $(\mathrm{R})$ residue in a particular helical domain called the SNARE domain. In general, Q- and RSNAREs reside on distinct membrane compartments, and three Q-SNAREs (Qa, Qb, and Qc) and an R-SNARE assemble into a tight complex in specific combinations, leading to membrane fusion between two compartments. Most SNARE proteins, except for SNAP-25-like members, contain one SNARE domain in their polypeptides (Jahn and Scheller, 2006). Recent comprehensive genomic analyses have indicated that a significant increase in the number of SNARE family members occurred with the acquisition of developmental complexity - for example, from unicellular to multicellular organisms (there are 17 SNAREs in C. merolae, 24 in S. cerevisiae, 26 in Chlamydomonas reinhardtii, 38 in H. sapiens, and 63 in A. thaliana; Dacks and Doolittle, 2002; Yoshizawa et al., 2006; Sanderfoot, 2007; Dacks et al., 2008). This increase is in good agreement with the hypothesis that multiplication followed by the functional diversification of key components of membrane trafficking, including SNAREs, is a prerequisite for the diversification of membrane trafficking pathways (Dacks and Doolittle, 2002; Yoshizawa et al., 2006; Dacks and Field, 2007; Dacks et al., 2008), which in turn should be required to support increasingly complex body plans and life cycles.

One remarkable feature of the post-Golgi SNARE in land plants is the functional diversification of the PM-localized Qa-SNARE, the SYP1 group, which consists of nine members in A. thaliana. Phylogenetic relationships to animal and fungal orthologs suggest that SYP1 group members are involved in membrane fusion at the PM (Sanderfoot, 2007); some members of SYP1 group have been reported to perform specialized functions at the PM. For example, SYP111/KNOLLE is expressed in mitotic cells and plays an essential role in membrane fusion at forming cell plates during cytokinesis (Lukowitz et al., 1996; Lauber et al., 1997). SYP121/PEN1/SYR1, another SYP1 member, takes part in $\mathrm{K}^{+}$ uptake through the control of $\mathrm{K}^{+}$channel gating (Honsbein et al., 2009; Grefen et al., 2010). This protein also participates in the nonhost defense response against attack by fungal pathogens (Collins et al., 2003; Assaad et al., 2004). SYP132 appears to be centrally involved in bacterial infection and symbiosis: the silencing of a SYP132 ortholog in Nicotiana benthamiana resulted in impaired multiple responses against bacterial pathogens (Kalde et al., 2007), and an ortholog of SYP132 in Medicago truncatula localizes to the PM surrounding infection threads and the infection droplet membrane (Catalano et al., 2007).

In addition to the functional diversification of SYP1 group members, another distinct feature of post-Golgi SNAREs in land plants is the expansion of the VAMP7 R-SNARE group (Sanderfoot, 2007; Ebine and Ueda, 2009). R-SNAREs are divided into two groups, longins and brevins; longins contain an N-terminal longin domain, while brevins lack this domain (Filippini et al., 2001). Land plants harbor only longin-type R-SNARE members, which are further classified into three major groups: VAMP7, YKT6, and SEC22. While vertebrates have only one or a few VAMP7 proteins that participate in secretory and endocytic trafficking (Chaineau et al., 2009), the VAMP7 group of A. thaliana consists of 12 members, which are further divided into three subgroups: VAMP71, VAMP72, and VAMP727 (Uemura et al., 2004). 
A phylogenic analysis has suggested that VAMP71 is a prototype from which VAMP72 and VAMP727 have been derived (Sanderfoot, 2007). VAMP71 members localize to the vacuolar membrane (Uemura et al., 2004) and are involved in salt and drought stress responses (Leshem et al., 2006, 2010). VAMP72 members localize to the TGN and function in the secretory pathway, including cell plate formation (Zhang et al., 2011). Although VAMP727 exhibits high sequence similarity to other VAMP72 members, it harbors a unique structural characteristic: VAMP727 has an insertion comprising acidic amino acid clusters in the longin domain (Ebine and Ueda, 2009; Vedovato et al., 2009). This type of VAMP7 member is well conserved in seed plants; however, it has not found in lycophytes or moss thus far, indicating relatively recent emergence of this subfamily.

VAMP727 localizes on the RAB5-positive MVE/pre-vacuolar compartment, and mediates membrane fusion between the prevacuolar compartment and vacuolar membranes by forming a complex with Qa-SYP22/VAM3, Qb-VTI11, and Qc-SYP51 (Ebine et al., 2008). This complex is essential for the efficient transport of storage proteins to protein storage vacuoles during the process of seed maturation. Moreover, VAMP727 also mediates membrane fusion at the PM by forming a complex with Qa-SYP121/PEN1 (Ebine et al., 2011), which is under the control of the plant-unique RAB5 ARA6. These lines of evidence may indicate that the plant explored novel trafficking pathways from the MVE to the vacuole and PM by acquiring these two plant-unique molecules, leading to the current complex and unique post-Golgi trafficking network in angiosperms.

\section{PERSPECTIVES}

Plants have elaborated a distinctive post-Golgi trafficking system through the acquisition of plant-specific machinery components

\section{REFERENCES}

Abbal, P., Pradal, M., Muniz, L., Sauvage, F. X., Chatelet, P., Ueda, T., and Tesniere, C. (2008). Molecular characterization and expression analysis of the Rab GTPase family in Vitis vinifera reveal the specific expression of a VvRabA protein. J. Exp. Bot. 59, 2403-2416.

Assaad, F. F., Qiu, J. L., Youngs, H., Ehrhardt, D., Zimmerli, L., Kalde, M., Wanner, G., Peck, S. C., Edwards, H., Ramonell, K., Somerville, C. R., and ThordalChristensen, H. (2004). The PEN1 syntaxin defines a novel cellular compartment upon fungal attack and is required for the timely assembly of papillae. Mol. Biol. Cell 15, 5118-5129.

Banks, J. A., Nishiyama, T., Hasebe, M., Bowman, J. L., Gribskov, M., dePamphilis, C., Albert, V. A., Aono, N., Aoyama, T., Ambrose, B. A., Ashton, N. W., Axtell, M. J., Barker, E., Barker, M. S., Bennetzen, J. L., Bonawitz, N. D., Chapple, C., Cheng, C., Correa, L. G. G., Dacre, M., DeBarry, J., Dreyer, I., Elias, M., Engstrom,
E. M., Estelle, M., Feng, L., Finet, C., Floyd, S. K., Frommer, W. B., Fujita, T., Gramzow, L., Gutensohn, M., Harholt, J., Hattori, M., Heyl, A., Hirai, T., Hiwatashi, Y., Ishikawa, M., Iwata, M., Karol, K. G., Koehler, B., Kolukisaoglu, U., Kubo, M., Kurata, T., Lalonde, S., Li, K., Li, Y., Litt, A., Lyons, E., Manning, G., Maruyama, T., Michael, T. P., Mikami, K., Miyazaki, S., Morinaga, S., Murata, T., Mueller-Roeber, B., Nelson, D. R., Obara, M., Oguri, Y., Olmstead, R. G., Onodera, N., Petersen, B. L., Pils, B., Prigge, M., Rensing, S. A., Riano-Pachon, D. M., Roberts, A. W., Sato, Y., Scheller, H. V., Schulz, B., Schulz, C., Shakirov, E. V., Shibagaki, N., Shinohara, N., Shippen, D. E., Sorensen, I., Sotooka, R., Sugimoto, N., Sugita, M., Sumikawa, N., Tanurdzic, M., Theissen, G., Ulvskov, P., Wakazuki, S., Weng, J. K., Willats, W. W., Wipf, D., Wolf, P. G., Yang, L., Zimmer, A. D., Zhu, Q., Mitros, T., Hellsten, U., Loque, D., Otillar, R., Salamov, A., Schmutz, J., Shapiro, H., Lindquist, E., Lucas, S., Rokhsar, D., and Grigoriev, I. V. (2011). The

of membrane trafficking, such as TPLATE, DRP1/2, ARA6, and VAMP727, as well as the functional expansion of evolutionarily conserved components, as observed for RAB11, EXO70, and SYP1 groups. However, many unsolved questions must be answered to elucidate the precise function and regulatory mechanism of the plant-unique trafficking system. For example, with what APs does TPLATE form a complex to mediate CCV formation? Does the TPLATE complex-mediated CCV formation involve DRP proteins? Why do land plants require two structurally distinct DRPs for CCV formation? Do they in fact polymerize into the same ring- or helix-shaped structure?

Regarding the molecular machinery involved in membrane tethering and fusion, key questions also remain to be elucidated. What effector molecules mediate ARA6 function to fulfill higherordered functions, such as salinity stress tolerance? Is the ARA6 function revealed in A. thaliana shared by all ARA6 group members throughout the plant lineages? Why and how did plants expand the RAB11 group, and how are different functions of RAB11 members exerted in spite of their high sequence similarity? What is the mechanism of molecular evolution of the VAMP727 group, and what is the molecular function of the acidic insertion? Additional studies using model systems like A. thaliana are obviously needed to answer these questions, and would also be required to challenge distinct lineages of plants, including basal lineages (e.g., ferns, mosses, liverworts, and algae), to yield information regarding aspects of diversity and evolution of membrane trafficking. Future experimental studies employing a wide variety of plant species, together with comprehensive genomics analysis in silico, will help us to understand how current plant membrane trafficking pathways have evolved.

Selaginella genome identifies genetic changes associated with the evolution of vascular plants. Science 332, 960-963.

Bar, M., Sharfman, M., Schuster, S., and Avni, A. (2009). The coiledcoil domain of EHD2 mediates inhibition of LeEix2 endocytosis and signaling. PLoS ONE 4, e7973. doi:10.1371/journal.pone.0007973

Barbrook, A. C., Howe, C. J., and Purton, S. (2006). Why are plastid genomes retained in nonphotosynthetic organisms? Trends Plant Sci. 11, 101-108.

Benli, M., Doring, F., Robinson, D. G., Yang, X., and Gallwitz, D. (1996). Two GTPase isoforms, Ypt31p and Ypt32p, are essential for Golgi function in yeast. $E M B O \mathrm{~J} .15$, 6460-6475.

Benmerah, A. (2004). Endocytosis: signaling from endocytic membranes to the nucleus. Curr. Biol. 14, R314R316.

Boehm, M., and Bonifacino, J. S. (2002). Genetic analyses of adaptin function from yeast to mammals. Gene 286, 175-186.
Bolte, S., Schiene, K., and Dietz, K. J. (2000). Characterization of a small GTP-binding protein of the rab 5 family in Mesembryanthemum crystallinum with increased level of expression during early salt stress. Plant Mol. Biol. 42, 923-936.

Bonifacino, J. S., and Glick, B. S. (2004). The mechanisms of vesicle budding and fusion. Cell 116, 153-166.

Bonifacino, J. S., and Traub, L. M. (2003). Signals for sorting of transmembrane proteins to endosomes and lysosomes. Annu. Rev. Biochem. 72, 395-447.

Boutte, Y., Frescatada-Rosa, M., Men, S., Chow, C. M., Ebine, K., Gustavsson, A., Johansson, L., Ueda, T., Moore, I., Jurgens, G., and Grebe, M. (2010). Endocytosis restricts Arabidopsis KNOLLE syntaxin to the cell division plane during late cytokinesis. EMBO J. 29, 546-558.

Brighouse, A., Dacks, J. B., and Field, M. C. (2010). Rab protein evolution and the history of the eukaryotic endomembrane system. Cell. Mol. Life Sci. 67, 3449-3465. 
Brodsky, F. M., Chen, C. Y., Knuehl, C., Towler, M. C., and Wakeham, D. E. (2001). Biological basket weaving: formation and function of clathrincoated vesicles. Annu. Rev. Cell Dev. Biol. 17, 517-568.

Burgos, P. V., Mardones, G. A., Rojas, A. L., Dasilva, L. L., Prabhu, Y., Hurley, J. H., and Bonifacino, J. S. (2010). Sorting of the Alzheimer's disease amyloid precursor protein mediated by the AP-4 complex. Dev. Cell 18, 425-436.

Burki, F., Inagaki, Y., Brate, J., Archibald, J. M., Keeling, P. J., Cavalier-Smith, T., Sakaguchi, M., Hashimoto, T., Horak, A., Kumar, S., Klaveness, D., Jakobsen, K. S., Pawlowski, J., and Shalchian-Tabrizi, K. (2009). Large-scale phylogenomic analyses reveal that two enigmatic protist lineages, telonemia and centroheliozoa, are related to photosynthetic chromalveolates. Genome Biol. Evol. 1, 231-238.

Burmann, F., Ebert, N., Van Baarle, S., and Bramkamp, M. (2011). A bacterial dynamin-like protein mediating nucleotide-independent membrane fusion. Mol. Microbiol. 79, 1294-1304.

Cai, H., Reinisch, K., and Ferro-Novick, S. (2007). Coats, tethers, Rabs, and SNAREs work together to mediate the intracellular destination of a transport vesicle. Dev. Cell 12, 671-682.

Catalano, C. M., Czymmek, K. J., Gann, J. G., and Sherrier, D. J. (2007). Medicago truncatula syntaxin SYP132 defines the symbiosome membrane and infection droplet membrane in root nodules. Planta 225, 541-550.

Cavalier-Smith, T. (1987). The origin of eukaryotic and archaebacterial cells. Ann. N. Y. Acad. Sci. 503, 17-54.

Cavalier-Smith, T. (2002). The phagotrophic origin of eukaryotes and phylogenetic classification of Protozoa. Int. J. Syst. Evol. Microbiol. 52, 297-354.

Chaineau, M., Danglot, L., and Galli, T. (2009). Multiple roles of the vesicular-SNARE TI-VAMP in postGolgi and endosomal trafficking. FEBS Lett. 583, 3817-3826.

Chanez, A. L., Hehl, A. B., Engstler, M., and Schneider, A. (2006). Ablation of the single dynamin of $\mathrm{T}$. brucei blocks mitochondrial fission and endocytosis and leads to a precise cytokinesis arrest. J. Cell. Sci. 119, 2968-2974.

Chen, W., Feng, Y., Chen, D., and Wandinger-Ness, A. (1998). Rab11 is required for trans-golgi networkto-plasma membrane transport and a preferential target for GDP dissociation inhibitor. Mol. Biol. Cell 9, 3241-3257.

Chen, X., Naramoto, S., Robert, S., Tejos, R., Lofke, C., Lin, D., Yang, Z., and Friml, J. (2012). ABP1 and ROP6 GTPase signaling regulate clathrinmediated endocytosis in Arabidopsis roots. Curr. Biol. 22, 1326-1332.

Chen, Y. A., and Scheller, R. H. (2001). SNARE-mediated membrane fusion. Nat. Rev. Mol. Cell Biol. 2, 98-106.

Chong, Y. T., Gidda, S. K., Sanford, C., Parkinson, J., Mullen, R. T., and Goring, D. R. (2010). Characterization of the Arabidopsis thaliana exocyst complex gene families by phylogenetic, expression profiling, and subcellular localization studies. New Phytol. 185, 401-419.

Chow, C. M., Neto, H., Foucart, C. and Moore, I. (2008). Rab-A2 and Rab-A3 GTPases define a trans-golgi endosomal membrane domain in Arabidopsis that contributes substantially to the cell plate. Plant Cell 20, 101-123.

Cole, R. A., Synek, L., Zarsky, V., and Fowler, J. E. (2005). SEC8, a subunit of the putative Arabidopsis exocyst complex, facilitates pollen germination and competitive pollen tube growth. Plant Physiol. 138, 2005-2018.

Coleman, J., Evans, D., Hawes, C., Horsley, D., and Cole, L. (1987). Structure and molecular-organization of higher-plant coated vesicles. J. Cell. Sci. 88, 35-45.

Collings, D. A., Gebbie, L. K., Howles, P. A., Hurley, U. A., Birch, R. J., Cork, A. H., Hocart, C. H., Arioli, T., and Williamson, R. E. (2008). Arabidopsis dynamin-like protein DRP1A: a null mutant with widespread defects in endocytosis, cellulose synthesis, cytokinesis, and cell expansion. J. Exp. Bot. 59, 361-376.

Collins, N. C., Thordal-Christensen, H., Lipka, V., Bau, S., Kombrink, E., Qiu, J. L., Huckelhoven, R., Stein, M., Freialdenhoven, A., Somerville, S. C., and Schulze-Lefert, P. (2003). SNARE-protein-mediated disease resistance at the plant cell wall. Nature 425, 973-977.

Crowther, R. A., and Pearse, B. M. (1981). Assembly and packing of clathrin into coats. J. Cell Biol. 91 , 790-797.

Dacks, J. B., and Doolittle, W. F. (2002). Novel syntaxin gene sequences from Giardia, Trypanosoma and algae: implications for the ancient evolution of the eukaryotic endomembrane system. J. Cell. Sci. 115, 1635-1642.
Dacks, J. B., and Field, M. C. (2007). Evolution of the eukaryotic membrane-trafficking system: origin, tempo and mode. J. Cell. Sci. 120, 2977-2985

Dacks, J. B., Peden, A. A., and Field, M. C. (2009). Evolution of specificity in the eukaryotic endomembrane system. Int. J. Biochem. Cell Biol. 41, 330-340.

Dacks, J. B., Poon, P. P., and Field, M. C. (2008). Phylogeny of endocytic components yields insight into the process of nonendosymbiotic organelle evolution. Proc. Natl. Acad. Sci. U.S.A. 105, 588-593.

de Graaf, B. H., Cheung, A. Y., Andreyeva, T., Levasseur, K., Kieliszewski, M., and Wu, H. M. (2005). Rab11 GTPase-regulated membrane trafficking is crucial for tip-focused pollen tube growth in tobacco. Plant Cell 17, 2564-2579.

Dell'Angelica, E. C. (2009). AP-3dependent trafficking and disease: the first decade. Curr. Opin. Cell Biol. 21, 552-559.

Dell'Angelica, E. C., Mullins, C., and Bonifacino, J. S. (1999). AP-4, a novel protein complex related to clathrin adaptors. J. Biol. Chem. 274 7278-7285.

Dell'Angelica, E. C., Ohno, H., Ooi, C E., Rabinovich, E., Roche, K. W., and Bonifacino, J. S. (1997). AP-3: an adaptor-like protein complex with ubiquitous expression. EMBO J. 16, 917-928.

Depta, H., Freundt, H., Hartmann, D., and Robinson, D. G. (1987). Preparation of a homogeneous coated vesicle fraction from bean-leaves. Protoplasma 136, 154-160.

Depta, H., and Robinson, D. G. (1986) The isolation and enrichment of coated vesicles from suspensioncultured carrot cells. Protoplasma $130,162-170$

Dettmer, J., Hong-Hermesdorf, A., Stierhof, Y. D., and Schumacher, K. (2006). Vacuolar H+-ATPase activity is required for endocytic and secretory trafficking in Arabidopsis. Plant Cell 18, 715-730.

Devos, D., Dokudovskaya, S., Alber, F., Williams, R., Chait, B. T., Sali, A., and Rout, M. P. (2004). Components of coated vesicles and nuclear pore complexes share a common molecular architecture. PLoS Biol. 2, e380. doi:10.1371/journal.bio.0020380

Dhonukshe, P., Aniento, F., Hwang, I., Robinson, D. G., Mravec, J., Stierhof, Y. D., and Friml, J. (2007). Clathrinmediated constitutive endocytosis of PIN auxin efflux carriers in Arabidopsis. Curr. Biol. 17, 520-527.
Dhonukshe, P., Tanaka, H., Goh, T., Ebine, K., Mahonen, A. P., Prasad, K., Blilou, I., Geldner, N., Xu, J., Uemura, T., Chory, J., Ueda, T. Nakano, A., Scheres, B., and Friml, J. (2008). Generation of cell polarity in plants links endocytosis, auxin distribution and cell fate decisions. Nature 456, 962-966.

Ebine, K., Fujimoto, M., Okatani, Y., Nishiyama, T., Goh, T., Ito, E., Dainobu, T., Nishitani, A., Uemura, T., Sato, M. H., Thordal-Christensen, H., Tsutsumi, N., Nakano, A., and Ueda, T. (2011). A membrane trafficking pathway regulated by the plant-specific RAB GTPase ARA6. Nat. Cell Biol. 13, 853-859.

Ebine, K., Miyakawa, N., Fujimoto, M., Uemura, T., Nakano, A., and Ueda, T. (2012). Endosomal trafficking pathway regulated by ARA6, a RAB5 GTPase unique to plants. Small GTPases 3, 0-4.

Ebine, K., Okatani, Y., Uemura, T., Goh, T., Shoda, K., Niihama, M., Morita, M. T., Spitzer, C., Otegui, M. S., Nakano, A., and Ueda, T. (2008). A SNARE complex unique to seed plants is required for protein storage vacuole biogenesis and seed development of Arabidopsis thaliana. Plant Cell 20, 3006-3021.

Ebine, K., and Ueda, T. (2009). Unique mechanism of plant endocytic/vacuolar transport pathways. J. Plant Res. 122, 21-30.

Elde, N. C., Morgan, G., Winey, M., Sperling, L., and Turkewitz, A. P. (2005). Elucidation of clathrin-mediated endocytosis in tetrahymena reveals an evolutionarily convergent recruitment of dynamin. PLoS Genet. 1, e52. doi:10.1371/journal.pgen.0010052

Elias, M. (2010). Patterns and processes in the evolution of the eukaryotic endomembrane system. Mol. Membr. Biol. 27, 469-489.

Elias, M., Brighouse, A., Castello, C. G., Field, M. C., and Dacks, J. B. (2012). Sculpting the endomembrane system in deep time: high resolution phylogenetics of Rab GTPases. $J$. Cell. Sci. 125, 2500-2508.

Elias, M., Drdova, E., Ziak, D., Bavlnka, B., Hala, M., Cvrckova F., Soukupova, H., and Zarsky, V. (2003). The exocyst complex in plants. Cell Biol. Int. 27, 199-201.

Embley, T. M., and Martin, W. (2006). Eukaryotic evolution, changes and challenges. Nature 440, 623-630.

Feraru, E., Paciorek, T., Feraru, M. I., Zwiewka, M., De Groodt, R., De Rycke, R., Kleine-Vehn, J., and Friml, J. (2010). The AP-3 beta adaptin mediates the biogenesis and 
function of lytic vacuoles in Arabidopsis. Plant Cell 22, 2812-2824.

Filippini, F., Rossi, V., Galli, T., Budillon, A., D’Urso, M., and D'Esposito, M. (2001). Longins: a new evolutionary conserved VAMP family sharing a novel SNARE domain. Trends Biochem. Sci. 26, 407-409.

Fu, Y., Gu, Y., Zheng, Z., Wasteneys, G., and Yang, Z. (2005). Arabidopsis interdigitating cell growth requires two antagonistic pathways with opposing action on cell morphogenesis. Cell 120, 687-700.

Fujimoto, M., Arimura, S., Nakazono, M., and Tsutsumi, N. (2008). Arabidopsis dynamin-related protein DRP2B is co-localized with DRP1A on the leading edge of the forming cell plate. Plant Cell Rep. 27, 1581-1586.

Fujimoto, M., Arimura, S., Ueda, T., Takanashi, H., Hayashi, Y., Nakano, A., and Tsutsumi, N. (2010). Arabidopsis dynamin-related proteins DRP2B and DRP1A participate together in clathrin-coated vesicle formation during endocytosis. Proc. Natl. Acad. Sci. U.S.A. 107, 6094-6099.

Goh, T., Uchida, W., Arakawa, S., Ito, E., Dainobu, T., Ebine, K., Takeuchi, M., Sato, K., Ueda, T., and Nakano, A. (2007). VPS9a, the common activator for two distinct types of Rab5 GTPases, is essential for the development of Arabidopsis thaliana. Plant Cell 19, 3504-3515.

Grefen, C., Chen, Z., Honsbein, A., Donald, N., Hills, A., and Blatt, M. R. (2010). A novel motif essential for SNARE interaction with the $\mathrm{K}(+)$ channel $\mathrm{KCl}$ and channel gating in Arabidopsis. Plant Cell 22, 3076-3092.

Grosshans, B. L., Ortiz, D., and Novick, P. (2006). Rabs and their effectors: achieving specificity in membrane traffic. Proc. Natl. Acad. Sci. U.S.A. 103, 11821-11827.

Guermonprez, H., Smertenko, A., Crosnier, M. T., Durandet, M., Vrielynck, N., Guerche, P., Hussey, P. J., SatiatJeunemaitre, B., and Bonhomme, S. (2008). The POK/AtVPS52 protein localizes to several distinct postGolgi compartments in sporophytic and gametophytic cells. J. Exp. Bot. 59, 3087-3098.

Gurkan, C., Koulov, A. V., and Balch, W. E. (2007). An evolutionary perspective on eukaryotic membrane trafficking. Adv. Exp. Med. Biol. 607, 73-83.

Haas, T. J., Sliwinski, M. K., Martinez, D. E., Preuss, M., Ebine, K., Ueda, T., Nielsen, E., Odorizzi, G., and Otegui, M. S. (2007). The Arabidopsis AAA
ATPase SKD1 is involved in multivesicular endosome function and interacts with its positive regulator LYST-INTERACTING PROTEIN5. Plant Cell 19, 1295-1312.

Hala, M., Cole, R., Synek, L., Drdova, E., Pecenkova, T., Nordheim, A., Lamkemeyer, T., Madlung, J., Hochholdinger, F., Fowler, J. E., and Zarsky, V. (2008). An exocyst complex functions in plant cell growth in Arabidopsis and tobacco. Plant Cell 20, 1330-1345.

Hanover, J. A., Willingham, M. C., and Pastan, I. (1984). Kinetics of transit of transferrin and epidermal growth factor through clathrin-coated membranes. Cell 39, 283-293.

Harris, K. P., and Tepass, U. (2008). $\mathrm{Cdc} 42$ and Par proteins stabilize dynamic adherens junctions in the Drosophila neuroectoderm through regulation of apical endocytosis. $J$. Cell Biol. 183, 1129-1143.

Heymann, J. A. W., and Hinshaw, J. E. (2009). Dynamins at a glance. J. Cell. Sci. 122, 3427-3431.

Hirst, J., Barlow, L. D., Francisco, G. C., Sahlender, D. A., Seaman, M. N., Dacks, J. B., and Robinson, M. S. (2011). The fifth adaptor protein complex. PLoS Biol. 9, e1001170. doi:10.1371/journal.pbio. 1001170

Hirst, J., Bright, N. A., Rous, B., and Robinson, M. S. (1999). Characterization of a fourth adaptor-related protein complex. Mol. Biol. Cell 10, 2787-2802.

Hong, Z., Bednarek, S. Y., Blumwald, E., Hwang, I., Jurgens, G., Menzel, D., Osteryoung, K. W., Raikhel, N. V., Shinozaki, K., Tsutsumi, N., and Verma, D. P. (2003). A unified nomenclature for Arabidopsis dynamin-related large GTPases based on homology and possible functions. Plant Mol. Biol. 53, 261-265.

Honsbein, A., Sokolovski, S., Grefen, C., Campanoni, P., Pratelli, R., Paneque, M., Chen, Z., Johansson, I., and Blatt, M. R. (2009). A tripartite SNARE-K+ channel complex mediates in channel-dependent $\mathrm{K}+$ nutrition in Arabidopsis. Plant Cell 21, 2859-2877.

Hu, J., Shibata, Y., Zhu, P. P., Voss, C., Rismanchi, N., Prinz, W. A., Rapoport, T. A., and Blackstone, C. (2009). A class of dynamin-like GTPases involved in the generation of the tubular ER network. Cell 138, 549-561.

Izumi, G., Sakisaka, T., Baba, T., Tanaka, S., Morimoto, K., and Takai, Y. (2004). Endocytosis of E-cadherin regulated by Rac and Cdc42 small
G proteins through IQGAP1 and actin filaments. J. Cell Biol. 166, 237-248.

Jackson, L. P., Kelly, B. T., Mccoy, A. J., Gaffry, T., James, L. C., Collins, B. M. Honing, S., Evans, P. R., and Owen, D. J. (2010). A large-scale conformational change couples membrane recruitment to cargo binding in the AP2 clathrin adaptor complex. Cell 141, 1220-1229.

Jahn, R., and Scheller, R. H. (2006) SNAREs - engines for membrane fusion. Nat. Rev. Mol. Cell Biol. 7, 631-643.

Jedd, G., Mulholland, J., and Segev, N. (1997). Two new Ypt GTPases are required for exit from the yeast trans-Golgi compartment. J. Cell Biol. 137, 563-580.

Kalde, M., Nuhse, T. S., Findlay, K., and Peck, S. C. (2007). The syntaxin SYP132 contributes to plant resistance against bacteria and secretion of pathogenesis-related protein 1. Proc. Natl. Acad. Sci. U.S.A. 104, 11850-11855.

Kang, B. H., Busse, J. S., and Bednarek, S. Y. (2003). Members of the Arabidopsis dynamin-like gene family, ADL1, are essential for plant cytokinesis and polarized cell growth. Plant Cell 15, 899-913.

Kleine-Vehn, J., Wabnik, K., Martiniere, A., Langowski, L., Willig, K., Naramoto, S., Leitner, J., Tanaka, H., Jakobs, S., Robert, S., Luschnig, C., Govaerts, W., Hell, S. W., Runions, J., and Friml, J. (2011). Recycling, clustering, and endocytosis jointly maintain PIN auxin carrier polarity at the plasma membrane. Mol. Syst. Biol. 7 , 540.

Konopka, C. A., Backues, S. K., and Bednarek, S. Y. (2008). Dynamics of Arabidopsis dynamin-related protein $1 \mathrm{C}$ and a clathrin light chain at the plasma membrane. Plant Cell 20, 1363-1380.

Koumandou, V. L., Dacks, J. B., Coulson, R. M., and Field, M. C. (2007). Control systems for membrane fusion in the ancestral eukaryote; evolution of tethering complexes and SM proteins. BMC Evol. Biol. 7, 29. doi:10.1186/1471-2148-7-29

Kulich, I., Cole, R., Drdova, E., Cvrckova, F., Soukup, A., Fowler, J., and Zarsky, V. (2010). Arabidopsis exocyst subunits SEC8 and EXO70A1 and exocyst interactor $\mathrm{ROH} 1$ are involved in the localized deposition of seed coat pectin. New Phytol. 188, 615-625.

Lauber, M. H., Waizenegger, I., Steinmann, T., Schwarz, H., Mayer, U., Hwang, I., Lukowitz, W., and Jurgens, G. (1997). The Arabidopsis
KNOLLE protein is a cytokinesisspecific syntaxin. J. Cell Biol. 139, 1485-1493.

Lee, C. F., Pu, H. Y., Wang, L. C., Sayler, R. J., Yeh, C. H., and Wu, S. J. (2006). Mutation in a homolog of yeast Vps53p accounts for the heat and osmotic hypersensitive phenotypes in Arabidopsis hit1-1 mutant. Planta 224, 330-338.

Lee, M. C., Miller, E. A., Goldberg, J., Orci, L., and Schekman, R. (2004). Bi-directional protein transport between the ER and Golgi. Annu. Rev. Cell Dev. Biol. 20, 87-123.

Leshem, Y., Golani, Y., Kaye, Y., and Levine, A. (2010). Reduced expression of the $\mathrm{v}$-SNAREs AtVAMP71/AtVAMP7C gene family in Arabidopsis reduces drought tolerance by suppression of abscisic acid-dependent stomatal closure. J. Exp. Bot. 61, 2615-2622.

Leshem, Y., Melamed-Book, N., Cagnac, O., Ronen, G., Nishri, Y., Solomon, M., Cohen, G., and Levine, A. (2006). Suppression of Arabidopsis vesicleSNARE expression inhibited fusion of $\mathrm{H} 2 \mathrm{O} 2$-containing vesicles with tonoplast and increased salt tolerance. Proc. Natl. Acad. Sci. U.S.A. 103, 18008-18013.

Lin, D., Nagawa, S., Chen, J., Cao, L., Chen, X., Xu, T., Li, H., Dhonukshe, P., Yamamuro, C., Friml, J., Scheres, B., Fu, Y., and Yang, Z. (2012). A ROP GTPase-dependent auxin signaling pathway regulates the subcellular distribution of PIN2 in Arabidopsis roots. Curr. Biol. 22, 1319-1325.

Lobstein, E., Guyon, A., Ferault, M., Twell, D., Pelletier, G., and Bonhomme, S. (2004). The putative Arabidopsis homolog of yeast vps $52 \mathrm{p}$ is required for pollen tube elongation, localizes to Golgi, and might be involved in vesicle trafficking. Plant Physiol. 135, 1480-1490.

Low, H. H., and Lowe, J. (2006). A bacterial dynamin-like protein. Nature 444, 766-769.

Lu, C., Zainal, Z., Tucker, G. A., and Lycett, G. W. (2001). Developmental abnormalities and reduced fruit softening in tomato plants expressing an antisense Rab11 GTPase gene. Plant Cell 13, 1819-1833.

Lukowitz, W., Mayer, U., and Jurgens, G. (1996). Cytokinesis in the Arabidopsis embryo involves the syntaxinrelated KNOLLE gene product. Cell 84, 61-71.

Lycett, G. (2008). The role of Rab GTPases in cell wall metabolism. $J$. Exp. Bot. 59, 4061-4074.

Macia, E., Ehrlich, M., Massol, R., Boucrot, E., Brunner, C., and Kirchhausen, T. (2006). Dynasore, 
a cell-permeable inhibitor of dynamin. Dev. Cell 10, 839-850.

Markgraf, D. F., Peplowska, K., and Ungermann, C. (2007). Rab cascades and tethering factors in the endomembrane system. FEBS Lett. 581, 2125-2130.

Matsuzaki, M., Misumi, O., Shin, I. T., Maruyama, S., Takahara, M., Miyagishima, S. Y., Mori, T., Nishida, K., Yagisawa, F., Yoshida, Y., Nishimura, Y., Nakao, S., Kobayashi, T., Momoyama, Y., Higashiyama, T., Minoda, A., Sano, M., Nomoto, H., Oishi, K., Hayashi, H., Ohta, F., Nishizaka, S., Haga, S., Miura, S., Morishita, T., Kabeya, Y., Terasawa, K., Suzuki, Y., Ishii, Y., Asakawa, S., Takano, H., Ohta, N., Kuroiwa, H., Tanaka, K., Shimizu, N., Sugano, S., Sato, N., Nozaki, H., Ogasawara, N., Kohara, Y., and Kuroiwa, T. (2004). Genome sequence of the ultrasmall unicellular red alga Cyanidioschyzon merolae 10D. Nature 428, 653-657.

McMahon, H. T., and Mills, I. G. (2004). COP and clathrin-coated vesicle budding: different pathways, common approaches. Curr. Opin. Cell Biol. 16, 379-391.

Mersey, B. G., Griffing, L. R., Rennie, P. J., and Fowke, L. C. (1985). The isolation of coated vesicles from protoplasts of soybean. Planta 163, 317-327.

Miyagishima, S. Y., Kuwayama, H., Urushihara, H., and Nakanishi, H. (2008). Evolutionary linkage between eukaryotic cytokinesis and chloroplast division by dynamin proteins. Proc. Natl. Acad. Sci. U.S.A. 105, 15202-15207.

Munson, M., and Novick, P. (2006). The exocyst defrocked, a framework of rods revealed. Nat. Struct. Mol. Biol. 13, 577-581.

Nagawa, S., Xu, T., Lin, D., Dhonukshe, P., Zhang, X., Friml, J., Scheres, B., Fu, Y., and Yang, Z. (2012). ROP GTPase-dependent actin microfilaments promote PIN1 polarization by localized inhibition of clathrin-dependent endocytosis. PLoS Biol. 10, e1001299. doi:10.1371/journal.pbio.1001299

Nagawa, S., Xu, T., and Yang, Z. (2010). RHO GTPase in plants: conservation and invention of regulators and effectors. Small GTPases 1, 78-88.

Napier, R. M., David, K. M., and PerrotRechenmann, C. (2002). A short history of auxin-binding proteins. Plant Mol. Biol. 49, 339-348.

Niihama, M., Takemoto, N., Hashiguchi, Y., Tasaka, M., and Morita, M. T. (2009). ZIP genes encode proteins involved in membrane trafficking of the TGN-PVC/vacuoles. Plant Cell Physiol. 50, 2057-2068.

Paciorek, T., Zazimalova, E., Ruthardt, N., Petrasek, J., Stierhof, Y. D., Kleine-Vehn, J., Morris, D. A., Emans, N., Jurgens, G., Geldner, N., and Friml, J. (2005). Auxin inhibits endocytosis and promotes its own efflux from cells. Nature 435, 1251-1256.

Pearse, B. M., and Robinson, M. S. (1984). Purification and properties of $100-\mathrm{kd}$ proteins from coated vesicles and their reconstitution with clathrin. EMBO J. 3 1951-1957.

Pecenkova, T., Hala, M., Kulich, I., Kocourkova, D., Drdova, E., Fendrych, M., Toupalova, H., and Zarsky, V. (2011). The role for the exocyst complex subunits Exo70B2 and Exo70H1 in the plant-pathogen interaction. J. Exp. Bot. 62, 2107-2116.

Pereira-Leal, J. B., and Seabra, M. C. (2001). Evolution of the Rab family of small GTP-binding proteins. J. Mol. Biol. 313, 889-901.

Praefcke, G. J., and McMahon, H. T. (2004). The dynamin superfamily: universal membrane tubulation and fission molecules? Nat. Rev. Mol. Cell Biol. 5, 133-147.

Preuss, M. L., Serna, J., Falbel, T. G., Bednarek, S. Y., and Nielsen, E. (2004). The Arabidopsis Rab GTPase RabA4b localizes to the tips of growing root hair cells. Plant Cell 16, 1589-1603.

Rensing, S. A., Lang, D., Zimmer, A. D., Terry, A., Salamov, A., Shapiro, H., Nishiyama, T., Perroud, P. F., Lindquist, E. A., Kamisugi, Y., Tanahashi, T., Sakakibara, K., Fujita, T., Oishi, K., Shin, I. T., Kuroki, Y., Toyoda, A., Suzuki, Y., Hashimoto, S., Yamaguchi, K., Sugano, S., Kohara, Y., Fujiyama, A., Anterola, A., Aoki, S., Ashton, N., Barbazuk, W. B., Barker, E., Bennetzen, J. L., Blankenship, R., Cho, S. H., Dutcher, S. K., Estelle, M., Fawcett, J. A., Gundlach, H., Hanada, K., Heyl, A., Hicks, K. A., Hughes, J., Lohr, M., Mayer, K., Melkozernov, A., Murata, T., Nelson, D. R., Pils, B., Prigge, M., Reiss, B., Renner, T., Rombauts, S., Rushton, P. J., Sanderfoot, A., Schween, G., Shiu, S. H., Stueber, K., Theodoulou, F. L., Tu, H., Van De Peer, Y., Verrier, P. J., Waters, E., Wood, A., Yang, L., Cove, D., Cuming, A. C., Hasebe, M., Lucas, S., Mishler, B. D., Reski, R., Grigoriev, I. V., Quatrano, R. S., and Boore, J. L. (2008). The Physcomitrella genome reveals evolutionary insights into the conquest of land by plants. Science 319, 64-69.
Robert, S., Kleine-Vehn, J., Barbez, E. Sauer, M., Paciorek, T., Baster, P., Vanneste, S., Zhang, J., Simon, S., Covanova, M., Hayashi, K., Dhonukshe, P., Yang, Z., Bednarek, S. Y. Jones, A. M., Luschnig, C., Aniento, F., Zazimalova, E., and Friml, J. (2010). ABP1 mediates auxin inhibition of clathrin-dependent endocytosis in Arabidopsis. Cell 143 111-121.

Robinson, M. S., and Bonifacino, J. S. (2001). Adaptor-related proteins. Curr. Opin. Cell Biol. 13, 444-453.

Robinson, M. S., Sahlender, D. A., and Foster, S. D. (2010). Rapid inactivation of proteins by rapamycininduced rerouting to mitochondria. Dev. Cell 18, 324-331.

Rojo, E., Gillmor, C. S., Kovaleva, V., Somerville, C. R., and Raikhel, N. V. (2001). VACUOLELESS1 is an essential gene required for vacuole formation and morphogenesis in Arabidopsis. Dev. Cell 1, 303-310.

Rojo, E., Zouhar, J., Kovaleva, V., Hong, S., and Raikhel, N. V. (2003). The AtC-VPS protein complex is localized to the tonoplast and the prevacuolar compartment in arabidopsis. Mol. Biol. Cell 14, 361-369.

Rutherford, S., and Moore, I. (2002). The Arabidopsis Rab GTPase family: another enigma variation. Curr. Opin. Plant Biol. 5, 518-528.

Saito, C., and Ueda, T. (2009). Chapter 4: functions of RAB and SNARE proteins in plant life. Int. Rev. Cell Mol. Biol. 274, 183-233.

Sanderfoot, A. (2007). Increases in the number of SNARE genes parallels the rise of multicellularity among the green plants. Plant Physiol. 144 6-17.

Schledzewski, K., Brinkmann, H., and Mendel, R. R. (1999). Phylogenetic analysis of components of the eukaryotic vesicle transport system reveals a common origin of adaptor protein complexes 1,2 , and 3 and the $\mathrm{F}$ subcomplex of the coatomer COPI. J. Mol. Evol. 48, 770-778.

Seabra, M. C., and Wasmeier, C. (2004). Controlling the location and activation of Rab GTPases. Curr. Opin. Cell Biol. 16, 451-457.

Segui-Simarro, J. M., Austin, J. R. II, White, E. A., and Staehelin, L. A. (2004). Electron tomographic analysis of somatic cell plate formation in meristematic cells of Arabidopsis preserved by high-pressure freezing. Plant Cell 16, 836-856.

Sever, S. (2002). Dynamin and endocytosis. Curr. Opin. Cell Biol. 14, 463-467.

Singh, B., and Gupta, R. S. (2004). Genomic organization and linkage via a bidirectional promoter of the AP-3 (adaptor protein-3) mu3A and AK (adenosine kinase) genes: deletion mutants of $\mathrm{AK}$ in Chinese hamster cells extend into the AP-3 mu3A gene. Biochem. J. 378, 519-528.

Somsel Rodman, J., and WandingerNess, A. (2000). Rab GTPases coordinate endocytosis. J. Cell. Sci. 113(Pt 2), 183-192.

Stenmark, H., and Olkkonen, V. M. (2001). The Rab GTPase family. Genome Biol. 2, REVIEWS3007.

Strickland, L. I., and Burgess, D. R. (2004). Pathways for membrane trafficking during cytokinesis. Trends Cell Biol. 14, 115-118.

Sweitzer, S. M., and Hinshaw, J. E. (1998). Dynamin undergoes a GTP-dependent conformational change causing vesiculation. Cell 93, 1021-1029.

Synek, L., Schlager, N., Elias, M., Quentin, M., Hauser, M. T., and Zarsky, V. (2006). AtEXO70Al, a member of a family of putative exocyst subunits specifically expanded in land plants, is important for polar growth and plant development. Plant J. 48, 54-72.

Szumlanski, A. L., and Nielsen, E. (2009). The Rab GTPase RabA4d regulates pollen tube tip growth in Arabidopsis thaliana. Plant Cell 21, 526-544.

Takei, K., Mcpherson, P. S., Schmid, S. L., and De Camilli, P. (1995). Tubular membrane invaginations coated by dynamin rings are induced by GTPgamma $\mathrm{S}$ in nerve terminals. Nature 374, 186-190.

Taylor, N. G. (2011). A role for Arabidopsis dynamin related proteins DRP2A/B in endocytosis; DRP2 function is essential for plant growth. Plant Mol. Biol. 76, 117-129.

Thellmann, M., Rybak, K., Thiele, K., Wanner, G., and Assaad, F. F. (2010). Tethering factors required for cytokinesis in Arabidopsis. Plant Physiol. 154, 720-732.

Ueda, T., Matsuda, N., Anai, T., Tsukaya, H., Uchimiya, H., and Nakano, A. (1996). An Arabidopsis gene isolated by a novel method for detecting genetic interaction in yeast encodes the GDP dissociation inhibitor of Ara4 GTPase. Plant Cell 8, 2079-2091.

Ueda, T., Uemura, T., Sato, M. H. and Nakano, A. (2004). Functional differentiation of endosomes in Arabidopsis cells. Plant J. 40, 783-789.

Ueda, T., Yamaguchi, M., Uchimiya, H., and Nakano, A. (2001). Ara6, a plant-unique novel type Rab GTPase, functions in the endocytic 
pathway of Arabidopsis thaliana. EMBO J. 20, 4730-4741.

Uemura, T., Ueda, T., Ohniwa, R. L., Nakano, A., Takeyasu, K., and Sato, M. H. (2004). Systematic analysis of SNARE molecules in Arabidopsis: dissection of the post-Golgi network in plant cells. Cell Struct. Funct. 29, 49-65.

Ullrich, O., Reinsch, S., Urbe, S., Zerial, M., and Parton, R. G. (1996). Rab11 regulates recycling through the pericentriolar recycling endosome. J. Cell Biol. 135, 913-924.

Van Damme, D., Coutuer, S., De Rycke, R., Bouget, F. Y., Inze, D., and Geelen, D. (2006). Somatic cytokinesis and pollen maturation in Arabidopsis depend on TPLATE, which has domains similar to coat proteins. Plant Cell 18, 3502-3518.

Van Damme, D., Gadeyne, A., Vanstraelen, M., Inze, D., Van Montagu, M. C., De Jaeger, G., Russinova, E., and Geelen, D. (2011). Adaptin-like protein TPLATE and clathrin recruitment during plant somatic cytokinesis occurs via two distinct pathways. Proc. Natl. Acad. Sci. U.S.A. 108, 615-620.

van Dooren, G. G., Reiff, S. B., Tomova, C., Meissner, M., Humbel, B. M., and Striepen, B. (2009). A novel dynamin-related protein has been recruited for apicoplast fission in Toxoplasma gondii. Curr. Biol. 19, 267-276.
Vedovato, M., Rossi, V., Dacks, J. B., and Filippini, F. (2009). Comparative analysis of plant genomes allows the definition of the "Phytolongins": a novel non-SNARE longin domain protein family. BMC Genomics 10, 510. doi:10.1186/1471-2164-10510

Vernoud, V., Horton, A. C., Yang, Z., and Nielsen, E. (2003). Analysis of the small GTPase gene superfamily of Arabidopsis. Plant Physiol. 131, 1191-1208.

Viotti, C., Bubeck, J., Stierhof, Y. D., Krebs, M., Langhans, M., Van Den Berg, W., Van Dongen, W., Richter, S., Geldner, N., Takano, J., Jurgens, G., De Vries, S. C., Robinson, D. G., and Schumacher, K. (2010). Endocytic and secretory traffic in Arabidopsis merge in the trans-Golgi network/early endosome, an independent and highly dynamic organelle. Plant Cell 22, 1344-1357.

Wang, J., Ding, Y., Hillmer, S., Miao, Y., Lo, S. W., Wang, X., Robinson, D. G., and Jiang, L. (2010). EXPO, an exocyst-positive organelle distinct from multivesicular endosomes and autophagosomes, mediates cytosol to cell wall exocytosis in Arabidopsis and tobacco cells. Plant Cell 22, 4009-4030.

Wickner, W., and Schekman, R. (2008). Membrane fusion. Nat. Struct. Mol. Biol. 15, 658-664.
Woollard, A. A., and Moore, I. (2008). The functions of Rab GTPases in plant membrane traffic. Curr. Opin. Plant Biol. 11, 610-619.

Xu, T., Wen, M., Nagawa, S., Fu, Y. Chen, J. G., Wu, M. J., PerrotRechenmann, C., Friml, J., Jones, A M., and Yang, Z. (2010). Cell surfaceand rho GTPase-based auxin signaling controls cellular interdigitation in Arabidopsis. Cell 143 99-110.

Yoshizawa, A. C., Kawashima, S., Okuda S., Fujita, M., Itoh, M., Moriya, Y., Hattori, M., and Kanehisa, M. (2006). Extracting sequence motifs and the phylogenetic features of SNARE-dependent membrane traffic. Traffic 7, 1104-1118

Yu, I. M., and Hughson, F. M. (2010) Tethering factors as organizers of intracellular vesicular traffic. Annu. Rev. Cell Dev. Biol. 26, 137-156.

Zainal, Z., Tucker, G. A., and Lycett, G. W. (1996). A rabll-like gene is developmentally regulated in ripening mango (Mangifera indica L.) fruit. Biochim. Biophys. Acta 1314 187-190.

Zhang, L., Tian, L. H., Zhao, J. F., Song, Y., Zhang, C. J., and Guo, Y. (2009). Identification of an apoplastic protein involved in the initial phase of salt stress response in rice root by two-dimensional electrophoresis. Plant Physiol. 149, 916-928.
Zhang, L., Zhang, H., Liu, P., Hao, H., Jin, J. B., and Lin, J. (2011). Arabidopsis R-SNARE proteins VAMP721 and VAMP722 are required for cell plate formation. PLoS ONE 6, e26129. doi:10.1371/journal.pone. 0026129

Conflict of Interest Statement: The authors declare that the research was conducted in the absence of any commercial or financial relationships that could be construed as a potential conflict of interest.

Received: 28 May 2012; accepted: 08 August 2012; published online: 28 August 2012.

Citation: Fujimoto $M$ and Ueda $T$ (2012) Conserved and plant-unique mechanisms regulating plant post-Golgi traffic. Front. Plant Sci. 3:197. doi: 10.3389/fpls.2012.00197

This article was submitted to Frontiers in Plant Traffic and Transport, a specialty of Frontiers in Plant Science.

Copyright (c) 2012 Fujimoto and Ueda. This is an open-access article distributed under the terms of the Creative Commons Attribution License, which permits use, distribution and reproduction in other forums, provided the original authors and source are credited and subject to any copyright notices concerning any third-party graphics etc. 